\title{
Anisotropic and trap-limited diffusion of hydrogen/deuterium in monoclinic gallium oxide single crystals
}

\author{
Vilde M. Reinertsen, ${ }^{1, \text { a) }}$ Philip M. Weiser, ${ }^{1,}$ b) Ymir K. Frodason, ${ }^{1}$ Marianne E. Bathen, ${ }^{1}$ \\ Lasse Vines, ${ }^{1}$ and Klaus Magnus Johansen ${ }^{1}$ \\ ${ }^{1}$ Centre for Material Science and Nanotechnology, Department of Physics, \\ University of Oslo, P.O. Box 1048, Blindern, Oslo, N-0316, \\ Norway
}

(Dated: 30 October 2020)

The effect of lattice anisotropy on the diffusion of hydrogen $(\mathrm{H}) /$ deuterium $\left({ }^{2} \mathrm{H}\right)$ in $\beta$ - $\mathrm{Ga}_{2} \mathrm{O}_{3}$ was investigated using secondary ion mass spectrometry (SIMS) and hybridfunctional calculations. Concentration-depth profiles of ${ }^{2} \mathrm{H}$-implanted single crystals show that ${ }^{2} \mathrm{H}$ can diffuse along the direction perpendicular to the (010) surface at temperatures as low as $300{ }^{\circ} \mathrm{C}$, whereas diffusion along the direction perpendicular to the $(-201)$ surface occurs only around $500{ }^{\circ} \mathrm{C}$. For both directions, the evolution of the ${ }^{2} \mathrm{H}$ concentration-depth profiles after heat treatments can be modeled by traplimited diffusion. Moreover, the traps can be present in the as-received crystals or created during ion implantation. Comparison of the experimentally-obtained binding energy for ${ }^{2} \mathrm{H}$ to the trap $(2.3 \pm 0.2 \mathrm{eV})$ with the binding energies determined from first-principles calculations suggests that intrinsic point defects (e.g., $\mathrm{V}_{\mathrm{Ga}}^{\mathrm{ib}}$ ) or defect complexes (e.g., $\mathrm{V}_{\mathrm{Ga}(2)} \mathrm{V}_{\mathrm{O}(2)}$ ), are excellent candidates for the trap and will play a crucial role for the diffusion of $\mathrm{H}$ or ${ }^{2} \mathrm{H}$ in $\beta-\mathrm{Ga}_{2} \mathrm{O}_{3}$.

\footnotetext{
a) V. M. Reinertsen and P. M. Weiser contributed equally to this work.

b)Electronic mail: p.m.weiser@smn.uio.no
} 
The large bandgap of 4.5-4.9 $\mathrm{eV}^{1-3}$ and ability to be doped $n$-type using $\mathrm{Sn}$ or $\mathrm{Si}^{4-12}$ makes monoclinic gallium oxide $\left(\beta-\mathrm{Ga}_{2} \mathrm{O}_{3}\right)$ a promising candidate for high-power electronics and UV-photo detectors. ${ }^{13-16}$ The precise control over the electrical and optical properties of a material needed for these applications demands a thorough understanding of the dominant point defects, and their effects on these properties, which is still in early development for $\beta$ - $\mathrm{Ga}_{2} \mathrm{O}_{3} \cdot{ }^{17,18}$ Hydrogen $(\mathrm{H})$ has emerged as an increasingly important impurity in $\beta-\mathrm{Ga}_{2} \mathrm{O}_{3}$. Indeed, unintentionally doped as-grown $\beta-\mathrm{Ga}_{2} \mathrm{O}_{3}$ crystals can exhibit free electron concentrations up to about $10^{18} \mathrm{~cm}^{-3}$ that originate from H-related defects. ${ }^{19}$ Theory predicts that interstitial $\mathrm{H}\left(\mathrm{H}_{i}\right)$ and $\mathrm{H}$ substituting at an oxygen site $\left(\mathrm{H}_{\mathrm{O}}\right)$ will behave as shallow donors $^{20}$, but $\mathrm{H}$ can also form complexes with other defects ${ }^{21}$ of both extrinsic and intrinsic type, thereby passivating their electrical activity. Infrared spectroscopy measurements of gas-hydrogenated or ion-implanted $\beta-\mathrm{Ga}_{2} \mathrm{O}_{3}$ single crystals reveal localized vibrational modes of O-H stretches originating from different H-related point defects, ${ }^{22-25}$ the most dominant one being a shifted gallium vacancy $\left(\mathrm{V}_{\mathrm{Ga}}^{\mathrm{ib}}\right)$ containing two $\mathrm{H}$ atoms $\left(\mathrm{V}_{\mathrm{Ga}}^{\mathrm{ib}}-2 \mathrm{H}\right) .{ }^{22,23,26}$ Recent investigations using deep-level transient spectroscopy show that the concentration of the deep-level $\mathrm{E}_{2}^{*}$ defect, ${ }^{27,28}$ which is associated with an intrinsic defect, can be decreased considerably by heat treatments in the presence of $\mathrm{H}$ under $n$-type conditions. ${ }^{29}$ This is important, since $\mathrm{E}_{2}^{*}$ was shown to be the main defect limiting the performance of $\beta$ - $\mathrm{Ga}_{2} \mathrm{O}_{3}$-based metal-semiconductor field-effect transistors. ${ }^{30}$ Furthermore, Islam et al. ${ }^{31}$ have reported observation of $p$-type conductivity, which could expand the application space of $\beta-\mathrm{Ga}_{2} \mathrm{O}_{3}$ considerably, and that was claimed to originate from H-related point defects created by specific sample treatments.

Recently, Polyakov and coworkers ${ }^{32}$ reported that the electrical properties of plasmahydrogenated $n$-type $\beta$ - $\mathrm{Ga}_{2} \mathrm{O}_{3}$ single crystals are radically different depending on the crystal's surface orientation. One potential explanation for this observation is differences in the fundamental diffusion properties of $\mathrm{H}$ along the different crystallographic directions. So far there are only a few reports that address the diffusion properties of $\mathrm{H}$ in $\beta-\mathrm{Ga}_{2} \mathrm{O}_{3}$. Ahn and coworkers ${ }^{33,34}$ studied deuterium $\left({ }^{2} \mathrm{H}\right)$ migration in both plasma-diffused and ionimplanted (-201)-oriented $\beta-\mathrm{Ga}_{2} \mathrm{O}_{3}$ single crystals using secondary-ion mass spectrometry (SIMS). It was found that a large fraction of the implanted ${ }^{2} \mathrm{H}$ out-diffused after 5 minutes in rapid thermal annealing, nominally at $650{ }^{\circ} \mathrm{C}$, leaving a fraction of ${ }^{2} \mathrm{H}$ trapped at residual implantation damage. In a subsequent study, Sharma et al. ${ }^{35}$ examined out-diffusion at 
additional annealing temperatures and determined a dissociation energy of $2.58 \mathrm{eV}$ for the release of ${ }^{2} \mathrm{H}$ from the traps. Their model assumed the out-diffusion of ${ }^{2} \mathrm{H}$ via the formation of molecules. Recently, Nickel and Geilert ${ }^{36}$ used SIMS to reveal inter-diffusion in the asgrown state for a layered structure of plasma assisted pulsed layer deposition (PLD)-grown $\mathrm{Ga}_{2} \mathrm{O}_{3}$. The sample was grown at $425{ }^{\circ} \mathrm{C}$, and the first layer was exposed to ${ }^{2} \mathrm{H}$ and the second to H. Interestingly, from hydrogen effusion measurements they found that the ratios between $\mathrm{H}-\mathrm{H},{ }^{2} \mathrm{H}-{ }^{2} \mathrm{H}$ and $\mathrm{H}^{2}{ }^{2} \mathrm{H}$ molecules were equal, which showed that the diffusion occurs mono-atomically and the formation of molecules occurs on the sample surface during the effusion process. However, due to the limited amount of available data, it was not possible to extract the full diffusion properties of $\mathrm{H}$ in $\mathrm{Ga}_{2} \mathrm{O}_{3}$.

In this work, the effect of crystal anisotropy on the diffusion of ${ }^{2} \mathrm{H}$ in ion-implanted $\beta$ $\mathrm{Ga}_{2} \mathrm{O}_{3}$ single crystals with either the (-201) or (010) surface orientation was systematically investigated after post-implantation heat treatments between 300 and $600{ }^{\circ} \mathrm{C}$. We find that ${ }^{2} \mathrm{H}$ diffusion is highly anisotropic, with diffusion along the [010] direction $\left(d_{\perp(010)}\right)$ occurring after heating at temperatures $(\mathrm{T}) \leq 300{ }^{\circ} \mathrm{C}$, whereas that along the direction perpendicular to the $(-201)$ surface $\left(d_{\perp(-201)}\right)$ begins after heat treatments at $500{ }^{\circ} \mathrm{C}$. For both surface orientations, the ${ }^{2} \mathrm{H}$ concentration-depth profiles are described by a model of trap-limited diffusion, where the redistribution of ${ }^{2} \mathrm{H}$ is strongly affected by traps present in the asreceived samples or created during ion implantation. Comparison of the binding energies between experiment and first-principles calculations suggests that intrinsic point defects and their complexes are strong candidates for traps, and play a crucial role on the diffusion of $\mathrm{H}$ and ${ }^{2} \mathrm{H}$ in $\beta-\mathrm{Ga}_{2} \mathrm{O}_{3}$.

The $\beta-\mathrm{Ga}_{2} \mathrm{O}_{3}$ samples studied in this work were $n$-type (Sn-doped) single-side polished crystals grown by the edge-defined film-fed growth method (Tamura Corporation, Japan). The samples had approximate dimensions $5 \mathrm{~mm} \times 5 \mathrm{~mm}, 500-700 \mu \mathrm{m}$ thickness, and either the (-201) or (010) surface orientation to monitor diffusion along the two different directions. ${ }^{2} \mathrm{H}$ was implanted from the polished surface at room temperature with fluences between $5 \times 10^{14} \mathrm{~cm}^{-2}$ and $4 \times 10^{15} \mathrm{~cm}^{-2}$. The implantation energy was chosen to be either 200 $\mathrm{keV}$ or $1.1 \mathrm{MeV}$, which resulted in implantation peaks at approximately 1.5 or $8.0 \mu \mathrm{m}$, respectively, below the sample surface as estimated using the Stopping and Range of Ions in Matter (SRIM) $\operatorname{code}^{37}$. Concentration-depth profiles of ${ }^{2} \mathrm{H}$ were acquired using a Cameca IMS7f SIMS microanalyzer equipped with a primary $\mathrm{Cs}^{+}$ion beam (15 keV energy, $100 \mathrm{nA}$ 
current) by rastering the beam over an area of $150 \mu \mathrm{m}^{2}$. A secondary ion field aperture (diameter of circular gated region $=33 \mu \mathrm{m}$ ) was employed to ensure detection at only the center of the sputtered crater bottom. The depth calibration was performed by measuring the sputtered crater using a Dektak 8 stylus profilometer and assuming a constant erosion rate. Unfortunately, the electrical conductivity at the surfaces of as-implanted samples was too low to perform SIMS measurements. However, heating the samples inside a tube furnace in air at temperatures between 300 and $350{ }^{\circ} \mathrm{C}$ for $20-30$ minutes improved the conductivity sufficiently to permit SIMS measurements. The depth profile of the sample in this state served as the reference measurement for the ${ }^{2} \mathrm{H}$ concentration calibration. We assume a negligible amount of ${ }^{2} \mathrm{H}$ out-diffused during this heat treatment, thus ensuring less than a $\pm 10 \%$ error in the absolute concentration. The samples were heat-treated subsequently in air for 30 minutes at temperatures up to $600{ }^{\circ} \mathrm{C}$, then removed from the furnace and cooled to room temperature in air outside the furnace.

Figure 1 shows ${ }^{2} \mathrm{H}$ concentration-depth profiles for a ${ }^{2} \mathrm{H}$-implanted (-201)-oriented $\beta$ $\mathrm{Ga}_{2} \mathrm{O}_{3}$ sample after heat treatments between 350 and $600{ }^{\circ} \mathrm{C}$. The diffusion profile for the lowest temperature $\left(350^{\circ} \mathrm{C}\right)$ shows a well-defined implantation peak similar to that expected from SRIM simulations, which indicates that ${ }^{2} \mathrm{H}$ does not diffuse along $d_{\perp(-201)}$ for $\mathrm{T} \leq 350$ ${ }^{\circ} \mathrm{C}$. Indeed, diffusion is not observed after heating the samples at temperatures up to and including $450{ }^{\circ} \mathrm{C}$. However, heat treatments $\geq 500{ }^{\circ} \mathrm{C}$ result in ${ }^{2} \mathrm{H}$ diffusion, which is evidenced by the increasing penetration of ${ }^{2} \mathrm{H}$ into the sample. Diffusion towards the surface of the sample is also observed for heat treatment in this temperature range. Interestingly, the ${ }^{2} \mathrm{H}$ concentration-depth profiles shown in Fig. 1 are similar in shape to the concentration-depth profiles observed for ${ }^{2} \mathrm{H}$ diffusion in $\mathrm{ZnO}$ and $\mathrm{H}$ diffusion in $\mathrm{SiC} .{ }^{38,39} \mathrm{In}$ both of these materials, the diffusion profiles were modeled best within the framework of trap-limited diffusion (TLD) ${ }^{39}$ which modifies Fick's second law of diffusion to include the capture and release of the diffusing species from a single dominant trap $(a)$, i.e., ${ }^{2} \mathrm{H}+a \rightleftharpoons{ }^{2} \mathrm{H} a$. The total concentration of the trap is assumed to remain unchanged during the diffusion process and is given by $\left[a_{\mathrm{tot}}\right]=\left[{ }^{2} \mathrm{H} a\right]+[a]$. Thus, the differential equation describing the change in the

${ }^{2} \mathrm{H}$ concentration with respect to time is given by,

$$
\frac{\partial\left[{ }^{2} \mathrm{H}\right]}{\partial t}=D \frac{\partial^{2}}{\partial x^{2}}\left[{ }^{2} \mathrm{H}\right]_{\mathrm{SS}}-\frac{\partial\left[{ }^{2} \mathrm{H} a\right]}{\partial t}
$$




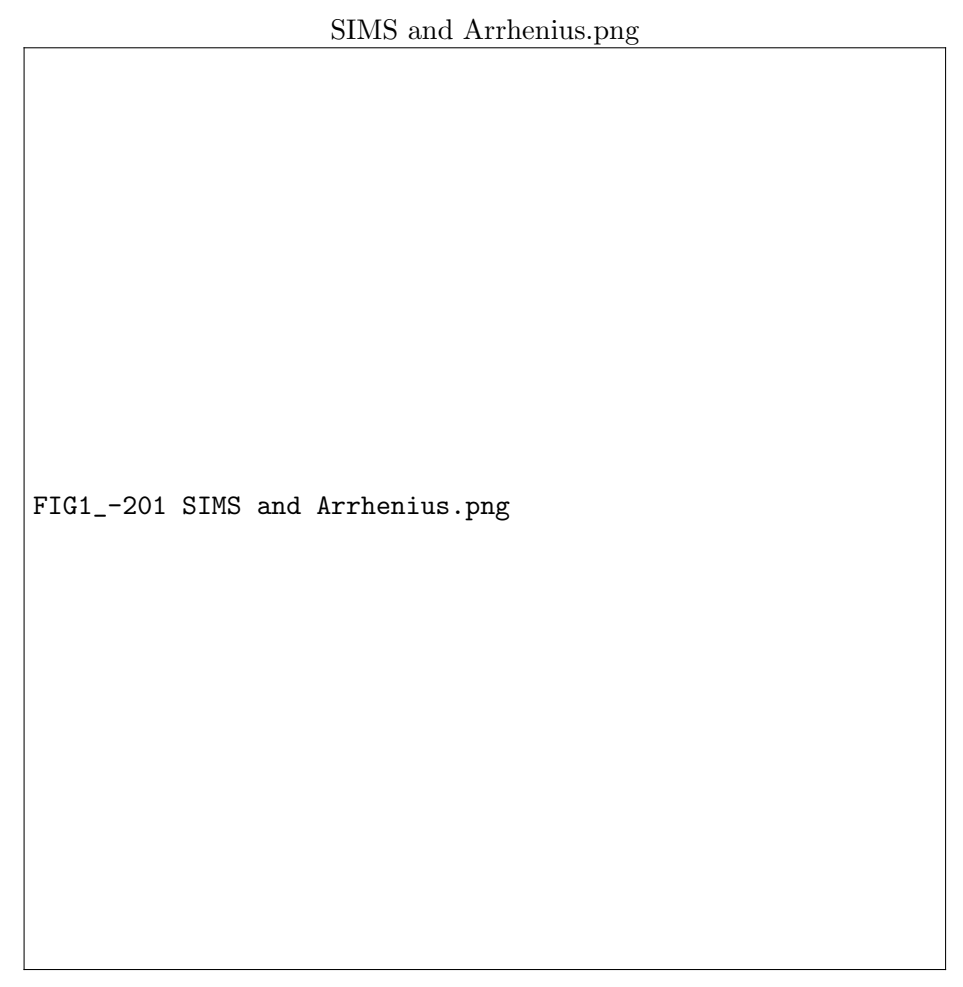

FIG. 1. ${ }^{2} \mathrm{H}$ concentration-depth profiles (unfilled points) for a (-201)-oriented $\beta-\mathrm{Ga}_{2} \mathrm{O}_{3}$ sample implanted with ${ }^{2} \mathrm{H}$ (energy $=200 \mathrm{keV}$, fluence $=4 \times 10^{15} \mathrm{~cm}^{-2}$ ) after 30 -min heat treatments at select temperatures between 350 and $600{ }^{\circ} \mathrm{C}$. The solid curves are fits to the data using the traplimited diffusion (TLD) model (eqn.(1)). Inset: Arrhenius plots of the ${ }^{2} \mathrm{H}$ diffusivity (left axis) and trap dissociation rate (right axis) determined from TLD fits at each temperature. Linear fits (solid lines) were used to determine the thermal activation energies and prefactors for ${ }^{2} \mathrm{H}$ diffusion and trap dissociation, respectively.

where,

$$
\frac{\partial\left[{ }^{2} \mathrm{H} a\right]}{\partial t}=\kappa\left[{ }^{2} \mathrm{H}\right]_{\mathrm{SS}}[a]-\nu\left[{ }^{2} \mathrm{H} a\right]
$$

In Eqns.(1) and (2), $\left[{ }^{2} \mathrm{Ha}\right]$ is the concentration of the filled trap state, $\left[{ }^{2} \mathrm{H}\right]_{\mathrm{SS}}$ is the amount of ${ }^{2} \mathrm{H}$ available from the source that is free to diffuse, ${ }^{38} \mathrm{D}$ is the diffusivity of the mobile ${ }^{2} \mathrm{H}$ species, $\kappa$ is a trapping rate given by $4 \pi R D$, and $\nu$ is the dissociation rate of the filled trap. 
The effective capture radius of the trap, $R$, was set to $5 \AA$, which is in the order of the lattice constant. Equation (1) was solved numerically using the partial differential equation solver flexPDE, ${ }^{40}$ treating $D$ and $\nu$ as fitting parameters. The total trap concentration $\left[a_{t o t}\right]$ was set in order to fit the height of the diffusion shoulder. The fits from the TLD model, shown as solid lines in Fig. 1, are in excellent agreement with the data, and capture especially well the steep decrease in the ${ }^{2} \mathrm{H}$ concentration deeper into the sample (i.e., the edge of the ${ }^{2} \mathrm{H}$ diffusion front). The inset of Fig. 1 shows Arrhenius plots for the values of $D$ (left axis) and $\nu$ (right axis) determined from the TLD fits. From the linear fits to $D$ and $\nu$ vs. $1 /$ T shown in Fig. 1, we determined activation energies for ${ }^{2} \mathrm{H}$ diffusion $\left(E_{m}\right)$ and trap dissociation $\left(E_{d}\right)$ of $1.9 \pm 0.2 \mathrm{eV}$ and $2.6 \pm 0.2 \mathrm{eV}$, respectively. Our $E_{d}$ is consistent with the value of $2.6 \mathrm{eV}$ reported by Sharma et al. ${ }^{35}$ whereas our $E_{m}$ is larger by about $0.7 \mathrm{eV}$. It should be noted that the prefactors for diffusion and dissociation rate can vary by an order of magnitude in either direction with very little impact on the activation energies. The prefactor for the dissociation rate of $7.5 \times 10^{13} \mathrm{~s}^{-1}$ is, however, quite close to the expected values calculated using the reported Debye temperatures of 738 and $872 \mathrm{~K}^{41,42} \mathrm{Ahn}$ et al. ${ }^{33,34}$ and Nickel and Geilert ${ }^{36}$ have reported diffusivities for ${ }^{2} \mathrm{H}$ of $6.4 \times 10^{-13} \mathrm{~cm}^{2} \mathrm{~s}^{-1}$ at $270{ }^{\circ} \mathrm{C}$ and $2.6 \times 10^{-13}$ $\mathrm{cm}^{2} \mathrm{~s}^{-1}$ at $425{ }^{\circ} \mathrm{C}$, respectively. Using our value of $D_{0}=310 \mathrm{~cm}^{2} \mathrm{~s}^{-1}$ (inset of Figure 1), we calculate ${ }^{2} \mathrm{H}$ diffusivities corresponding to $7.3 \times 10^{-16} \mathrm{~cm}^{2} \mathrm{~s}^{-1}$ and $6.0 \times 10^{-12} \mathrm{~cm}^{2} \mathrm{~s}^{-1}$ at 270 ${ }^{\circ} \mathrm{C}$ and $425{ }^{\circ} \mathrm{C}$, respectively. We speculate that the differences in $E_{m}$ 's and ${ }^{2} \mathrm{H}$ diffusivities between our data and the values reported in the literature ${ }^{33-36}$ originate from differences in the sample type (PLD-grown thin films vs. bulk single crystals), heat treatments (rapid thermal processing vs. conventional thermal annealing), and trapping model.

The ${ }^{2} \mathrm{H}$ concentration-depth profiles for a shallow-implanted (010) $\beta-\mathrm{Ga}_{2} \mathrm{O}_{3}$ sample after heat treatments between 300 and $575{ }^{\circ} \mathrm{C}$ are shown in Fig. 2(a). There are two distinct differences between these concentration-depth profiles and those observed for the (-201)oriented samples. First, the post-implantation heat treatment at $300{ }^{\circ} \mathrm{C}$ for the $(010)$ sample results in a shoulder on the shallow side of the implantation peak; no such shoulder was observed for the (-201) sample until it was heat-treated at $500{ }^{\circ} \mathrm{C}$. Second, the height of the ${ }^{2} \mathrm{H}$ implantation peak decreases strongly for heat treatments $\geq 500{ }^{\circ} \mathrm{C}$ in the $(010)$ sample, whereas it remains essentially constant in the (-201) sample. Both of these observations indicate that the monoclinic lattice plays a significant role on ${ }^{2} \mathrm{H}$ diffusion in $\beta-\mathrm{Ga}_{2} \mathrm{O}_{3}$, with diffusion more favorable along $d_{\perp(010)}$ than along $d_{\perp(-201)}$. One potential explanation for 


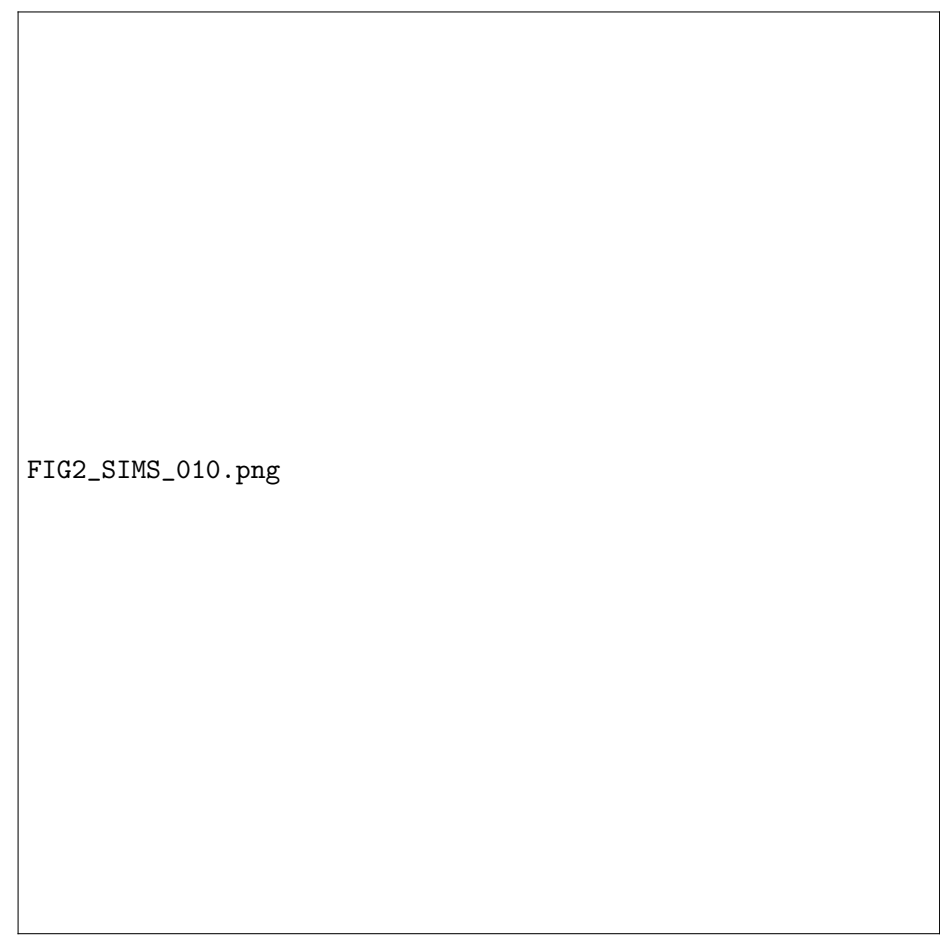

FIG. 2. (a) ${ }^{2} \mathrm{H}$ concentration-depth profiles (unfilled points) for a (010)-oriented $\beta-\mathrm{Ga}_{2} \mathrm{O}_{3}$ sample implanted with ${ }^{2} \mathrm{H}$ (energy $=200 \mathrm{keV}$, fluence $=5 \times 10^{14} \mathrm{~cm}^{-2}$ ) after 30 -min heat treatments at select temperatures between 300 and $575{ }^{\circ} \mathrm{C}$. (b) ${ }^{2} \mathrm{H}$ concentration-depth profiles (unfilled points) for the same (010)-oriented sample shown in (a) after a second ${ }^{2} \mathrm{H}$ implantation (energy=1.1 MeV, fluence $=2 \times 10^{15} \mathrm{~cm}^{-2}$ ) and subsequent heat treatments between 300 and $355{ }^{\circ} \mathrm{C}$. Fits for each temperature using the TLD model are shown as solid curves. The concentration of $\mathrm{V}_{\mathrm{Ga}}$ 's generated by the ${ }^{2} \mathrm{H}$ implantation was simulated using $\mathrm{SRIM}^{37}$ (dashed blue curve) and assumes that $2 \%$ of the vacancies do not annihilate.

this is the open channels along $d_{\perp(010)}$ that might facilitate $\mathrm{H}_{i}^{+}$diffusion via cross-channel jumps between $\mathrm{O}$ sites (Fig. 3). These channels are unavailable along $d_{\perp(-201)}$, which will presumably result in higher energy barriers for diffusion along this direction. Similar effects of lattice anisotropy have been reported for $\mathrm{H}_{i}^{+}$diffusion in rutile $\mathrm{TiO}_{2}$, in which $\mathrm{H}_{i}^{+}$diffusion in open channels along the $c$ axis is more favorable than in the $a-b$ plane. ${ }^{43}$ 


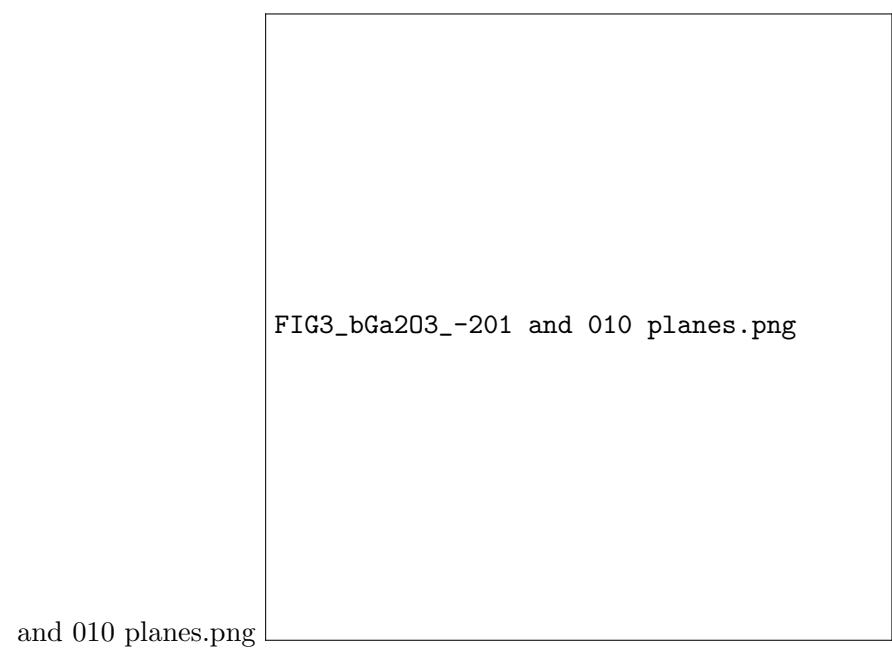

FIG. 3. Structure of $\beta-\mathrm{Ga}_{2} \mathrm{O}_{3}$. The (010) and (-201) planes are shown in light grey and magenta, respectively. The black arrows are the directions perpendicular to these planes, $d_{\perp(010)}$ and $d_{\perp(-201)}$. The atoms are color-coded as follows: $\mathrm{Ga}(1)=$ dark blue, $\mathrm{Ga}(2)=$ light blue, $\mathrm{O}(1)=$ light red, $\mathrm{O}(2)=$ red, and $\mathrm{O}(3)=$ dark red. The crystallographic orientation is shown to the right of the structure. Figure produced by VESTA. ${ }^{44}$

Additional investigations, however, are needed to establish the precise mechanism(s) by which $\mathrm{H}_{i}^{+}$diffusion occurs along the different crystallographic directions of $\beta-\mathrm{Ga}_{2} \mathrm{O}_{3}$.

Unlike the ${ }^{2} \mathrm{H}$ distribution observed in the (-201) samples, the profiles in the (010) samples do not show a significant ${ }^{2} \mathrm{H}$ concentration into the bulk. One possible explanation for the missing observation of ${ }^{2} \mathrm{H}$ is that the trap concentration is substantially lower than that in the (-201) sample, i.e., below the detection limit of SIMS for ${ }^{2} \mathrm{H}$. Interestingly, on the shallow side of the implantation peak, where a significant amount of ion-induced defects are created, a distinct increase in the ${ }^{2} \mathrm{H}$ concentration is observed after heat treatments $\geq$ $500{ }^{\circ} \mathrm{C}$. This observation suggests that ${ }^{2} \mathrm{H}$ is trapped by intrinsic defects created during ion implantation as it diffuses towards the sample surface, thus accumulating to a concentration well above the detection limit of SIMS for ${ }^{2} \mathrm{H}$. To test this hypothesis, a second implantation was made deeper into the same (010) sample after its heat treatment at $575{ }^{\circ} \mathrm{C}$ (Fig. 2(a), unfilled green diamonds). The sample was subsequently heat-treated between 300 and 355 
${ }^{\circ} \mathrm{C}$, with SIMS measurements performed after each heat treatment (Fig. 2(b)). Indeed, the ${ }^{2} \mathrm{H}$ concentration-depth profile after the $300{ }^{\circ} \mathrm{C}$ heating exhibits a shoulder on the shallow side of the deep implantation peak, which is consistent with ${ }^{2} \mathrm{H}$ diffusion having a lower energy barrier along $d_{\perp(010)}$ than along $d_{\perp(-201)}$. As the heat-treatment temperature is increased, we observe a significant diffusion of ${ }^{2} \mathrm{H}$ towards the surface. In fact, after the heat treatment at $355{ }^{\circ} \mathrm{C}$, the ${ }^{2} \mathrm{H}$ diffusion front has almost reached the position of the shallow implantation peak. The ${ }^{2} \mathrm{H}$ diffusion after the heat treatments between $325{ }^{\circ} \mathrm{C}$ and $355{ }^{\circ} \mathrm{C}$ can be modeled by Eqn. (1), which implies that TLD of ${ }^{2} \mathrm{H}$ also occurs along $d_{\perp(010)}$.

Unfortunately, the small heating steps $(\Delta \mathrm{T} \approx 10 \mathrm{~K})$ and narrow temperature range prevent reliable determination of parameters for ${ }^{2} \mathrm{H}$ diffusivity and trap dissociation parameters along $d_{\perp(010)}$. Furthermore, the environment where ${ }^{2} \mathrm{H}$ undergoes TLD in the (010) sample is expected to be more complex than that present in the bulk of the $(-201)$ sample due to implantation damage. Note that the concentration of $\mathrm{V}_{\mathrm{Ga}}$, which has been shown to be the dominant trapping defect for ${ }^{2} \mathrm{H},{ }^{22,23}$ is, based on SRIM simulations, expected to vary by almost one order of magnitude in the region where TLD is observed. ${ }^{37}$ This variation in the trap concentration is not accounted for during the fit of the TLD model and prevents us from determining reliable fit parameters for ${ }^{2} \mathrm{H}$ diffusion along $d_{\perp(010)}$. Nevertheless, we conclude that the TLD model partially captures ${ }^{2} \mathrm{H}$ diffusion along $d_{\perp(010)}$.

The results from the (010) sample clearly show that the introduction of intrinsic defects into the sample provides traps for ${ }^{2} \mathrm{H}$ diffusion, where $\mathrm{V}_{\mathrm{Ga}}$ is one of the prime candidates. Moreover, recent positron annihilation spectroscopy results ${ }^{45}$ suggest that as-grown $\beta$ - $\mathrm{Ga}_{2} \mathrm{O}_{3}$ single crystals can contain considerable concentrations of shifted $\mathrm{V}_{\mathrm{Ga}}$, which is consistent with the ${ }^{2} \mathrm{H}$ concentration-depth profiles shown in Figure 1. To investigate this further, we have calculated binding energies for several H-related defect complexes using the HeydScuseria-Ernzerhof (HSE) hybrid functional ${ }^{46}$ and the project augmented-wave method, ${ }^{47-49}$ as implemented in the Vienna Ab initio Simulation Package (VASP) code. ${ }^{50,51}$ The fraction of screened Hartree-Fock exchange was set to 0.33 and all calculations were performed with the semicore $\mathrm{Ga} 3 \mathrm{~d}$ electrons treated as explicit valence electrons. Defect calculations were carried out using 160-atom supercells, a plane-wave energy cutoff of $500 \mathrm{eV}$, and a single special k-point at $(0.25,0.25,0.25) .{ }^{52}$ For charged defects, the total energies were corrected using the anisotropic ${ }^{53}$ scheme of Freysoldt-Neugebauer-Van de Walle. ${ }^{54,55}$ Defect formation energies $\left(E^{f}\right)$ were calculated using the well-established formalism described in Ref. ${ }^{56}$. Bind- 
ing energies were calculated as the difference in $E^{f}$ between the H-decorated complex, and the sum of the $E^{f}$ 's of $\mathrm{H}_{i}^{+}$and the remaining defect when a single $\mathrm{H}$ is removed from the complex. For example, the binding energy of the $\left(\mathrm{V}_{\mathrm{Ga}}^{\mathrm{ib}} 2 \mathrm{H}\right)^{-1}$ complex is given by,

$$
E^{b}\left[\left(V_{\mathrm{Ga}}^{\mathrm{ib}} 2 \mathrm{H}\right)^{-}\right]=\left(E^{f}\left[\mathrm{H}_{i}^{+}\right]+E^{f}\left[\left(V_{\mathrm{Ga}}^{\mathrm{ib}} \mathrm{H}\right)^{2-}\right]\right)-E^{f}\left[\left(V_{\mathrm{Ga}}^{\mathrm{ib}} 2 \mathrm{H}\right)^{-}\right],
$$

where the sign is chosen such that a positive binding energy indicates a stable $\mathrm{H}$-complex. Binding energies are calculated assuming $n$-type material (Fermi-level position at the conduction band minimum). The calculated $\mathrm{H}$ binding energies for selected $\mathrm{H}$-related defect

TABLE I. Binding energies for various hydrogenated defects in $n$-type $\beta$ - $\mathrm{Ga}_{2} \mathrm{O}_{3}$

\begin{tabular}{cc}
\hline \hline Defect reaction & Binding energy $(\mathrm{eV})$ \\
\hline$\left(\mathrm{V}_{\mathrm{Ga}}^{\mathrm{ib}} \mathrm{H}\right)^{2-} \rightarrow\left(\mathrm{V}_{\mathrm{Ga}}^{\mathrm{ib}}\right)^{3-}+\mathrm{H}_{i}^{+}$ & 2.94 \\
$\left(\mathrm{~V}_{\mathrm{Ga}}^{\mathrm{ib}} 2 \mathrm{H}\right)^{-} \rightarrow\left(\mathrm{V}_{\mathrm{Ga}}^{\mathrm{ib}} \mathrm{H}\right)^{2-}+\mathrm{H}_{i}^{+}$ & 2.62 \\
$\left(\mathrm{~V}_{\mathrm{Ga}}^{\mathrm{ib}} 3 \mathrm{H}\right)^{0} \rightarrow\left(\mathrm{V}_{\mathrm{Ga}}^{\mathrm{ib}} 2 \mathrm{H}\right)^{-}+\mathrm{H}_{i}^{+}$ & 0.73 \\
$\left(\mathrm{~V}_{\mathrm{Ga}}^{\mathrm{ib}} 4 \mathrm{H}\right)^{+} \rightarrow\left(\mathrm{V}_{\mathrm{Ga}}^{\mathrm{ib}} 3 \mathrm{H}\right)^{0}+\mathrm{H}_{i}^{+}$ & 0.44 \\
$\mathrm{H}_{\mathrm{O}(2)}^{+} \rightarrow \mathrm{V}_{\mathrm{O}(2)}^{0}+\mathrm{H}_{i}^{+}$ & 0.34 \\
$\mathrm{H}_{\mathrm{O}(2)}^{-} \rightarrow \mathrm{V}_{\mathrm{O}(2)}^{2-}+\mathrm{H}_{i}^{+}$ & 0.82 \\
$\left(\mathrm{~V}_{\mathrm{Ga}(2)} \mathrm{H}_{-} \mathrm{V}_{\mathrm{O}(2)}\right)^{2-} \rightarrow\left(\mathrm{V}_{\mathrm{Ga}(2)} \mathrm{V}_{\mathrm{O}(2)}\right)^{3-}+\mathrm{H}_{i}^{+}$ & 2.48 \\
$\left(\mathrm{Mg} \mathrm{Ga}_{(2)} \mathrm{H}\right)^{0} \rightarrow \mathrm{Mg}_{\mathrm{Ga}(2)}^{-}+\mathrm{H}_{i}^{+}$ & 0.68 \\
$\left(\mathrm{~N}_{\mathrm{O}(1)} \mathrm{H}\right)^{0} \rightarrow \mathrm{N}_{\mathrm{O}(1)}^{-}+\mathrm{H}_{i}^{+}$ & 2.18 \\
\hline \hline
\end{tabular}

complexes are listed in Table I. The values for $\mathrm{V}_{\mathrm{Ga}}^{\mathrm{ib}} \mathrm{H}, \mathrm{V}_{\mathrm{Ga}}^{\mathrm{ib}} 2 \mathrm{H}$, and $\mathrm{Mg}_{\mathrm{Ga}(2)} \mathrm{H}$ are in good agreement with other hybrid functional calculations reported in Refs. ${ }^{21,24}$ and $^{28}$. An estimate of the trap binding energy $\left(E_{b}\right)$ from experiment can be determined from $E_{b}=E_{d}-E_{m}$, where $E_{d}$ is the trap dissociation energy $(2.6 \pm 0.2 \mathrm{eV})$ and $E_{m}$ is the lowest migration energy available to $\mathrm{H}_{i}^{+}$. Since $E_{m}$ for $\mathrm{H}_{i}^{+}$along $d_{\perp(010)}$ cannot be determined from our data, we use the reported value of $0.34 \mathrm{eV}$ computed by Varley et al. ${ }^{21}$ which results in $E_{b}=2.3 \pm 0.2$ $\mathrm{eV}$. Comparison of this value with the values listed in Table I suggest that $\mathrm{V}_{\mathrm{Ga}}^{\mathrm{ib}} 2 \mathrm{H}$ and $\mathrm{V}_{\mathrm{Ga}(2)} \mathrm{H}-\mathrm{V}_{\mathrm{O}(2)}$, which are the lowest energy configurations for $\mathrm{V}_{\mathrm{Ga}} 2 \mathrm{H}$ and $\mathrm{V}_{\mathrm{Ga}} \mathrm{H}-\mathrm{V}_{\mathrm{O}}$-type defects, respectively, are excellent candidates for the filled trap. The $E_{b}$ 's of $\mathrm{V}_{\mathrm{Ga}}^{\mathrm{ib}} 3 \mathrm{H}$ and $\mathrm{V}_{\mathrm{Ga}}^{\mathrm{ib}} 4 \mathrm{H}$, which were recently shown ${ }^{57}$ to be more likely than the corresponding structures consisting of unshifted $\mathrm{V}_{\mathrm{Ga}(1)},{ }^{31}$ are considerably lower than our experimental $E_{b}$, and are 
therefore excluded. Both the negative and positive charge states of $\mathrm{H}_{\mathrm{O}(2)}$ are excluded as candidates for the trap, also due to their low $E_{b}$ 's. ${ }^{58}$ Alternatively, the hydrogen-passivated $\mathrm{N}$-acceptor complex ( $\mathrm{N}$ substituting at an $\mathrm{O}(1)$ site) also has an $E_{b}{ }^{59}$ that falls within the range of $E_{b}$ determined from our data. However, the concentration of $\mathrm{N}$ impurities in the as-received single crystals is below the detection limit of our SIMS measurements $\left(<10^{17}\right.$ $\mathrm{cm}^{-3}$ ) and therefore excluded as the dominant trap in these samples.

In summary, we have shown that the diffusion of ${ }^{2} \mathrm{H}$ in $\beta-\mathrm{Ga}_{2} \mathrm{O}_{3}$ single crystals is highly anisotropic: diffusion along $d_{\perp(010)}$ occurs already at $300{ }^{\circ} \mathrm{C}$, whereas that along $d_{\perp(-201)}$ starts at $500{ }^{\circ} \mathrm{C}$. The evolution of the ${ }^{2} \mathrm{H}$ concentration-depth profiles after heat treatments for both directions is well described by a model of trap-limited diffusion. From the (-201) data, we determined a migration energy for ${ }^{2} \mathrm{H}$ along $d_{\perp(-201)}$ of $1.9 \pm 0.2 \mathrm{eV}$ and a trap dissociation energy of $2.6 \pm 0.2 \mathrm{eV}$. The binding energy of ${ }^{2} \mathrm{H}$ to the trap determined from experiment is similar to the calculated binding energies of $\mathrm{H}$-containing intrinsic defects, including $\mathrm{V}_{\mathrm{Ga}}^{\mathrm{ib}} 2 \mathrm{H}$ and $\mathrm{V}_{\mathrm{Ga}(2)} \mathrm{H}-\mathrm{V}_{\mathrm{O}(2)}$. Based on these data, we tentatively conclude that $\mathrm{V}_{\mathrm{Ga}}$ and the divacancy act as a trap for $\mathrm{H}$ diffusion in $\beta-\mathrm{Ga}_{2} \mathrm{O}_{3}$. As a consequence of this, ${ }^{2} \mathrm{H}$ may be used as a probe for $\mathrm{V}_{\mathrm{Ga}}$-related defects in $\beta-\mathrm{Ga}_{2} \mathrm{O}_{3}$. Although our model implies that there are differences between the initial $\mathrm{V}_{\mathrm{Ga}}$-related defect concentrations in the (-201)- and (010)-oriented crystals studied in this work, a systematic study, using other techniques that can detect these defects directly, on an extensive sample set would be needed to substantiate this claim. Such differences could have important implications for $\beta-\mathrm{Ga}_{2} \mathrm{O}_{3}$ crystal growth and device fabrication.

This work was supported by the Research Council of Norway through the Norwegian Micro- and Nano-Fabrication Facility (NorFab, project number 245963), the FUNDAMENT project (project number 251131), and the Research Center for Sustainable Solar Cell Technology (FME SUSOLTECH, project number 257639). The Faculty of Mathematics and Natural Sciences at the University of Oslo is also acknowledged for their support via the strategic research initiative FOXHOUND. The data that support the findings of this study are available from the corresponding author upon reasonable request. 


\section{REFERENCES}

${ }^{1}$ H. H. Tippins, "Optical Absorption and Photoconductivity in the Band Edge of $\beta-\mathrm{Ga}_{2} \mathrm{O}_{3}$," Phys. Rev. 140, A316-A319 (1965).

${ }^{2}$ M. Orita, H. Ohta, M. Hirano, and H. Hosono, "Deep-ultraviolet transparent conductive $\beta-\mathrm{Ga}_{2} \mathrm{O}_{3}$ thin films," Applied Physics Letters 77, 4166-4168 (2000), https://doi.org/10.1063/1.1330559.

${ }^{3}$ C. Janowitz, V. Scherer, M. Mohamed, A. Krapf, H. Dwelk, R. Manzke, Z. Galazka, R. Uecker, K. Irmscher, R. Fornari, M. Michling, D. Schmeiser, J. R. Weber, J. B. Varley, and C. G. Van de Walle, "Experimental electronic structure of $\operatorname{In}_{2} \mathrm{O}_{3}$ and $\mathrm{Ga}_{2} \mathrm{O}_{3}$," New Journal of Physics 13, 085014 (2011).

${ }^{4}$ N. Ueda, H. Hosono, R. Waseda, and H. Kawazoe, "Anisotropy of electrical and optical properties in $\beta-\mathrm{Ga}_{2} \mathrm{O}_{3}$ single crystals," Applied Physics Letters 71, 933-935 (1997), https://doi.org/10.1063/1.119693.

${ }^{5}$ Y. Usui, D. Nakauchi, N. Kawano, G. Okada, N. Kawaguchi, and T. Yanagida, "Scintillation and optical properties of Sn-doped $\mathrm{Ga}_{2} \mathrm{O}_{3}$ single crystals," Journal of Physics and Chemistry of Solids 117, 36-41 (2018).

${ }^{6}$ A. Kuramata, K. Koshi, S. Watanabe, Y. Yamaoka, T. Masui, and S. Yamakoshi, "Highquality $\beta-\mathrm{Ga}_{2} \mathrm{O}_{3}$ single crystals grown by edge-defined film-fed growth," Japanese Journal of Applied Physics 55, 1202A2 (2016).

${ }^{7} \mathrm{~S}$. Ohira and N. Arai, "Wet chemical etching behavior of $\beta$ $\mathrm{Ga}_{2} \mathrm{O}_{3}$ single crystal," physica status solidi c $\quad \mathbf{5}, \quad 3116-3118$ (2008), https://onlinelibrary.wiley.com/doi/pdf/10.1002/pssc.200779223.

${ }^{8}$ J. Zhang, C. Zia, Q. Deng, W. Xu, H. Shi, F. Wu, and J. Xu, "Growth and characterization of new transparent conductive oxides single crystals $\beta-\mathrm{Ga}_{2} \mathrm{O}_{3}$ :Sn," Journal of Physics and Chemistry of Solids 67, 1656-1659 (2006).

${ }^{9}$ Z. Galazka, R. Uecker, D. Klimm, K. Irmscher, M. Naumann, M. Pietsch, A. Kwasniewski, R. Bertram, S. Ganschow, and M. Bickermann, "Scaling-Up of bulk $\beta-\mathrm{Ga}_{2} \mathrm{O}_{3}$ Single Crystals by the Czochralski Method," ECS Journal of Solid State Science and Technology 6, Q3007 (2017).

${ }^{10}$ K. Shimamura, E. G. Víllora, T. Ujiie, and K. Aoki, "Excitation and photoluminescence of pure and Si-doped $\beta-\mathrm{Ga}_{2} \mathrm{O}_{3}$ single crystals," Applied Physics Letters 92, 201914 (2008), 
https://doi.org/10.1063/1.2910768.

${ }^{11}$ E. G. Víllora, K. Shimamura, Y. Yoshikawa, T. Ujiie, and K. Aoki, "Electrical conductivity and carrier concentration control in $\beta-\mathrm{Ga}_{2} \mathrm{O}_{3}$ by Si doping," Applied Physics Letters 92, 202120 (2008), https://doi.org/10.1063/1.2919728.

${ }^{12}$ T. Oshima, A. Kaminaga, K. Mukai, K. Sasaki, T. Masui, A. Kuramata, S. Yamakoshi, S. Fujita, and A. Ohtomo, "Formation of Semi-Insulating Layers on Semiconducting $\beta$ $\mathrm{Ga}_{2} \mathrm{O}_{3}$ Single Crystals by Thermal Oxidation," Japanese Journal of Applied Physics 52, 051101 (2013).

${ }^{13} \mathrm{Z}$. Galazka, " $\beta-\mathrm{Ga}_{2} \mathrm{O}_{3}$ for wide-bandgap electronics and optoelectronics," Semiconductor Science and Technology 33, 113001 (2018).

${ }^{14} \mathrm{M}$. Higashiwaki and G. H. Jessen, "Guest Editorial: The dawn of gallium oxide microelectronics," Applied Physics Letters 112, 060401 (2018), https://doi.org/10.1063/1.5017845.

${ }^{15}$ S. J. Pearton, J. Yang, P. H. Cary IV, F. Ren, J. Kim, M. J. Tadjer, and M. A. Mastro, “A review of $\mathrm{Ga}_{2} \mathrm{O}_{3}$ materials, processing, and devices," Applied Physics Reviews 5, 011301 (2018), https://doi.org/10.1063/1.5006941.

${ }^{16}$ M. Baldini, Z. Galazka, and G. Wagner, "Recent progress in the growth of $\beta-\mathrm{Ga}_{2} \mathrm{O}_{3}$ for power electronics applications," Materials Science in Semiconductors Processing 78, 132-146 (2018).

${ }^{17}$ M. D. McCluskey, "Point defects in $\mathrm{Ga}_{2} \mathrm{O}_{3}$," Journal of Applied Physics 127, 101101 (2020).

${ }^{18}$ M. Tadjer, J. Lyons, N. Nepal, J. A. Freitas Jr., A. Koehler, and G. M. Foster, "Theory and Characterization of Doping and Defects in $\beta-\mathrm{Ga}_{2} \mathrm{O}_{3}$," ECS Journal of Solid State Science and Technology 8, Q33187 (2019).

${ }^{19}$ Z. Galazka, K. Irmscher, R. Schewski, I. M. Hanke, M. Pietsch, S. Ganschow, D. Klimm, A. Dittmar, A. Fiedler, T. Schroeder, and M. Bickermann, "Czochralski-grown bulk $\beta$ $\mathrm{Ga}_{2} \mathrm{O}_{3}$ single crystals doped with mono-, di-, tri-, and tetravalent ions," Journal of Crystal Growth 529, 125297 (2020).

${ }^{20}$ J. B. Varley, J. R. Weber, A. Janotti, and C. G. Van de Walle, "Oxygen vacancies and donor impurities in $\beta-\mathrm{Ga}_{2} \mathrm{O}_{3}, "$ Applied Physics Letters 97, 142106 (2010).

${ }^{21}$ J. B. Varley, H. Peelaers, A. Janotti, and C. G. Van de Walle, "Hydrogenated cation vacancies in semiconducting oxides," Journal of Physics: Condensed Matter 23, 334212 (2011). 
${ }^{22}$ P. Weiser, M. Stavola, W. B. Fowler, Y. Qin, and S. Pearton, "Structure and vibrational properties of the dominant $\mathrm{O}-\mathrm{H}$ center in $\beta-\mathrm{Ga}_{2} \mathrm{O}_{3}$," Applied Physics Letters 112, 232104 (2018).

${ }^{23}$ Y. Qin, M. Stavola, W. B. Fowler, P. Weiser, and S. J. Pearton, "Hydrogen centers in $\beta-\mathrm{Ga}_{2} \mathrm{O}_{3}$ : Infrared Spectroscopy and Density Functional Theory," ECS Journal of Solid State Science and Technology 8, Q3103-Q3110 (2019).

${ }^{24}$ J. R. Ritter, J. Huso, P. T. Dickens, J. B. Varley, K. G. Lynn, and M. D. McCluskey, "Compensation and hydrogen passivation of magnesium acceptors in $\beta-\mathrm{Ga}_{2} \mathrm{O}_{3}$," Applied Physics Letters 113, 052101 (2018).

${ }^{25}$ J. R. Ritter, K. G. Lynn, and M. D. McCluskey, "Iridium-related complexes in Czochralskigrown $\beta-\mathrm{Ga}_{2} \mathrm{O}_{3}$," Journal of Applied Physics 126, 225705 (2019).

${ }^{26}$ A. Portoff, A. Venzie, M. Stavola, W. B. Fowler, and S. J. Pearton, "Determination of dielectric axes and transition moment directions in $\beta-\mathrm{Ga}_{2} \mathrm{O}_{3}$ from the polarization dependence of vibrational spectra," Journal of Applied Physics 127, 055702 (2019).

${ }^{27}$ M. E. Ingebrigtsen, J. B. Varley, A. Y. Kuznetsov, B. G. Svensson, G. Alfieri, A. Mihaila, U. Badstübner, and L. Vines, "Iron and intrinsic deep level states in $\mathrm{Ga}_{2} \mathrm{O}_{3}$," Applied Physics Letters 112, 042104 (2018).

${ }^{28}$ M. E. Ingebrigtsen, A. Y. Kuznetsov, B. G. Svensson, G. Alfieri, A. Mihaila, U. Badstübner, A. Perron, L. Vines, and J. B. Varley, "Impact of proton irradiation on conductivity and deep level defects in $\beta-\mathrm{Ga}_{2} \mathrm{O}_{3}$," APL Materials 7, 022510 (2019).

${ }^{29}$ C. Zimmermann, E. F. Verhoeven, Y. K. Frodason, P. M. Weiser, J. B. Varley, and L. Vines, "Formation and control of the $\mathrm{E}_{2}^{*}$ center in implanted $\beta-\mathrm{Ga}_{2} \mathrm{O}_{3}$ by reverse-bias and zero-bias annealing," Journal of Physics D: Applied Physics 53, 464001 (2020).

${ }^{30}$ J. F. McGlone, Z. Xia, C. Joishi, S. Lodha, S. Rajan, S. Ringel, and A. R. Arehart, "Identification of critical buffer traps in Si $\delta$-doped $\beta$ - $\mathrm{Ga}_{2} \mathrm{O}_{3}$ MESFETs," Applied Physics Letters 115, 153501 (2019).

${ }^{31}$ M. M. Islam, M. O. Liedke, D. Winarski, M. Butterling, A. Wagner, P. Hosemann, Y. Wang, B. Uberuaga, and F. A. Selim, "Chemical manipulation of hydrogen induced high p-type and n-type conductivity in $\mathrm{Ga}_{2} \mathrm{O}_{3}$," Scientific Reports 10, 6134 (2020).

${ }^{32}$ A. Y. Polyakov, I.-H. Lee, A. Miakonkikh, A. V. Chernykh, N. B. Smirnov, I. V. Shchemerov, A. I. Kochkova, A. A. Vasilev, and S. J. Pearton, "Anisotropy of hydrogen plasma effects in bulk n-type $\beta$ - $\mathrm{Ga}_{2} \mathrm{O}_{3}$," Journal of Applied Physics 127, 175702 (2020). 
${ }^{33}$ S. Ahn, F. Ren, E. Patrick, M. E. Law, S. J. Pearton, and A. Kuramata, "Deuterium incorporation and diffusivity in plasma-exposed bulk ga2o3," Applied Physics Letters 109, 242108 (2016), https://doi.org/10.1063/1.4972265.

${ }^{34}$ S. Ahn, F. R., E. Patrick, M. E. Law, S. J. Pearton, and A. Kuramata, "Thermal stability of implanted or plasma exposed deuterium in single crystal $\mathrm{Ga}_{2} \mathrm{O}_{3}$," ECS Journal of Solid State Science and Technology 6, Q3026-Q3029 (2017).

${ }^{35}$ R. Sharma, E. Patrick, M. E. Law, S. Ahn, F. Ren, S. J. Pearton, and A. Kuramata, "Extraction of migration energies and role of implant damage on thermal stability of deuterium in $\mathrm{Ga}_{2} \mathrm{O}_{3}$," ECS Journal of Solid State Science and Technology 6, P794-P797 (2017).

${ }^{36}$ N. H. Nickel and K. Geilert, "Monatomic hydrogen diffusion in $\beta-\mathrm{Ga}_{2} \mathrm{O}_{3}$," Applied Physics Letters 116, 242102 (2020).

${ }^{37}$ J. F. Ziegler and J. P. Biersack, "SRIM-2013 software package," see http://www.srim.org (2013).

${ }^{38}$ K. M. Johansen, J. S. Christensen, E. V. Monakhov, A. Y. Kuznetsov, and B. G. Svensson, "Deuterium diffusion and trapping in hydrothermally grown single crystalline $\mathrm{ZnO}$," Applied Physics Letters 93, 152109 (2008).

${ }^{39}$ M. S. Janson, A. Hallén, M. K. Linnarsson, and B. G. Svensson, "Hydrogen diffusion, complex formation, and dissociation in acceptor-doped silicon carbide," Physical Review B 64, 195202 (2001).

${ }^{40}$ FlexPDE, "Solutions inc," see http://www.pdesolutions.com (2015).

${ }^{41}$ Z. Guo, A. Verma, X. Wu, F. Sun, A. Hickman, T. Masui, A. Kuramata, M. Higashiwaki, D. Jena, and T. Luo, "Anisotropic thermal conductivity in single crystal $\beta$-gallium oxide," Applied Physics Letters 106, 111909 (2015), https://doi.org/10.1063/1.4916078.

${ }^{42}$ H. He, M. A. Blanco, and R. Pandey, "Electronic and thermodynamic properties of $\beta-\mathrm{Ga}_{2} \mathrm{O}_{3}, "$ Applied Physics Letters 88, 261904 (2006), https://doi.org/10.1063/1.2218046.

${ }^{43}$ J. B. Bates, J. C. Wang, and R. A. Perkins, "Mechanisms for hydrogen diffusion in $\mathrm{TiO}_{2}$," Physical Review B 19, 4130-4139 (1979).

${ }^{44} \mathrm{~K}$. Momma and F. Izumi, "VESTA3 for three-dimensional visualization of crystal, volumetric and morphology data," Journal of Applied Crystallography 44, 1272-1276 (2011).

${ }^{45}$ A. Karjalainen, V. Prozheeva, K. Simula, I. Makkonen, V. Callewaert, J. B. Varley, and 
F. Tuomisto, "Split Ga vacancies and the colossal anisotropy of positron annihilation spectra in $\beta-\mathrm{Ga}_{2} \mathrm{O}_{3}, "$ (2020), arXiv:2005.06283 [cond-mat.mtrl-sci].

${ }^{46}$ A. V. Krukau, O. A. Vydrov, A. F. Izmaylov, and G. E. Scuseria, "Influence of the exchange screening parameter on the performance of screened hybrid functionals," The Journal of Chemical Physics 125, 224106 (2006).

${ }^{47}$ P. E. Blöchl, "Projector augmented-wave method," Physical Review B 50, 17953 (1994).

${ }^{48} \mathrm{G}$. Kress and J. Hafner, "Norm-conserving and ultrasoft psuedopotentials for first-row and transition elements," Journal of Physics: Condensed Matter 6, 8245 (1994).

${ }^{49} \mathrm{G}$. Kress and D. Joubert, "From ultrasoft pseudopotentials to the projector augmentedwave method," Physical Review B 59, 1758 (1999).

${ }^{50}$ G. Kresse and J. Hafner, "Ab initio molecular dynamics for liquid metals," Physical Review B 47, 558-561 (1993).

${ }^{51}$ G. Kresse and J. Furthmüller, "Efficient iterative schemes for ab initio total-energy calculations using a plane-wave basis set," Physical Review B 54, 11169-11186 (1996).

${ }^{52}$ A. Baldereschi, "Mean-value point in the brillouin zone," Phys. Rev. B 7, 5212-5215 (1973).

${ }^{53}$ Y. Kumagai and F. Oba, "Electrostatics-based finite-size corrections for first-principles point defect calculations," Physical Review B 89, 195205 (2014).

${ }^{54}$ C. Freysoldt, J. Neugebauer, and C. G. Van de Walle, "Fully Ab Initio finite-size corrections for charged-defect supercell calculations," Physical Review Letters 102, 016402 (2009).

${ }^{55}$ H.-P. Komsa, T. T. Rantala, and A. Pasquarello, "Finite-size supercell correction schemes for charged defect calculations," Physical Review B 86, 045112 (2012).

${ }^{56}$ C. Freysoldt, B. Grabowski, T. Hickel, J. Neugebauer, G. Kresse, A. Janotti, and C. G. Van de Walle, "First-principles calculations for point defects in solids," Rev. Mod. Phys. 86, 253-305 (2014).

${ }^{57}$ W. B. Fowler, M. Stavola, Y. Qin, and P. Weiser, "Trapping of multiple H atoms at the $\mathrm{Ga}(1)$ vacancy in $\beta-\mathrm{Ga}_{2} \mathrm{O}_{3}, "$ Applied Physics Letters 117, 142101 (2020), https://doi.org/10.1063/5.0024269.

${ }^{58}$ C. Zimmermann, E. F. Verhoeven, P. M. Weiser, Y. K. Frodason, J. B. Varley, I. Kolevatov, and L. Vines, "Hydrogenation of $\beta-\mathrm{Ga}_{2} \mathrm{O}_{3}$ : Influence on deep-level defects," submitted (2020). 
${ }^{59}$ Y. K. Frodason, K. M. Johansen, L. Vines, and J. B. Varley, "Self-trapped hole and impurity-related broad luminescence in $\beta-\mathrm{Ga}_{2} \mathrm{O}_{3}$," Journal of Applied Physics 127, 075701 (2020), https://doi.org/10.1063/1.5140742. 


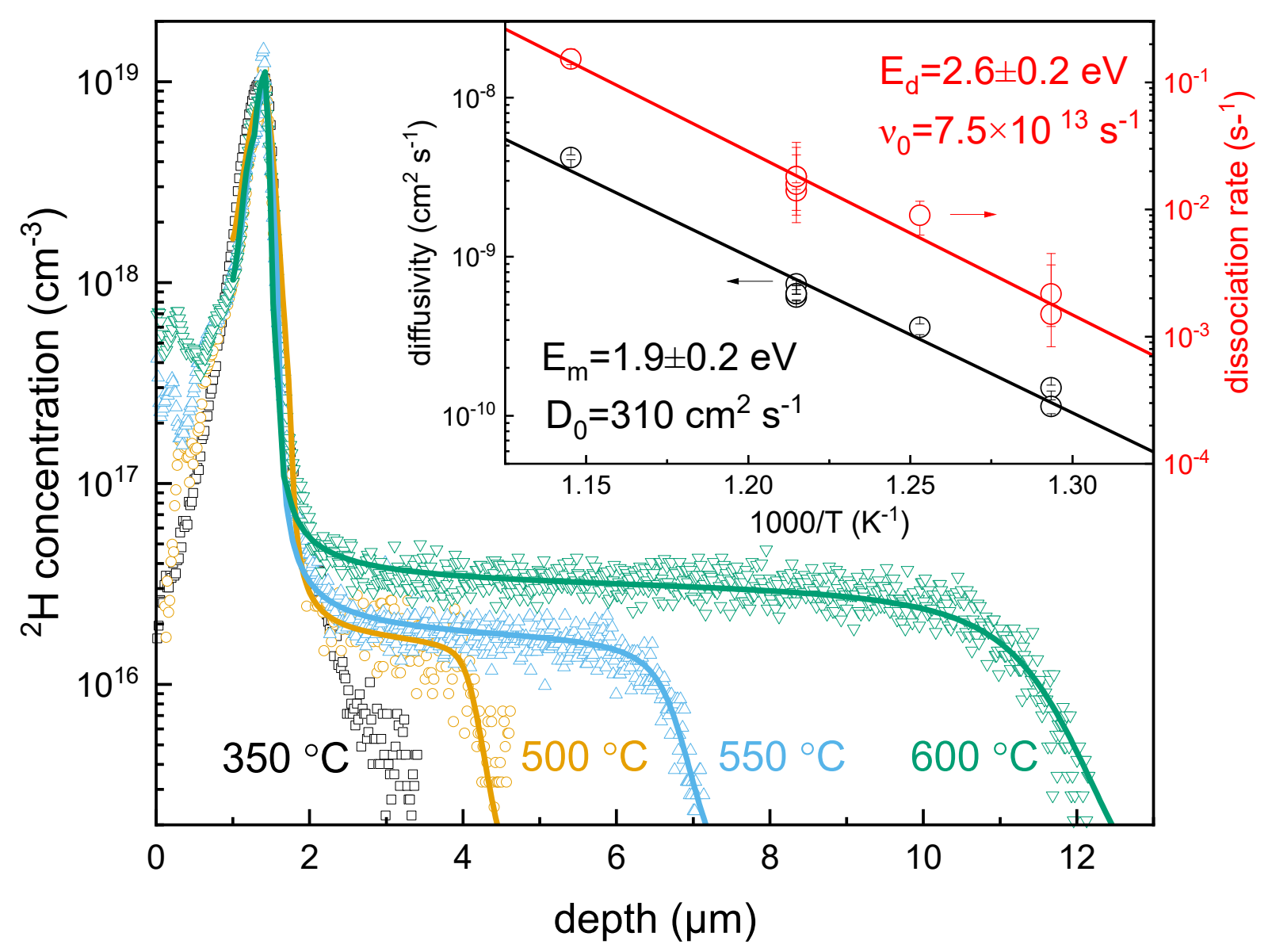



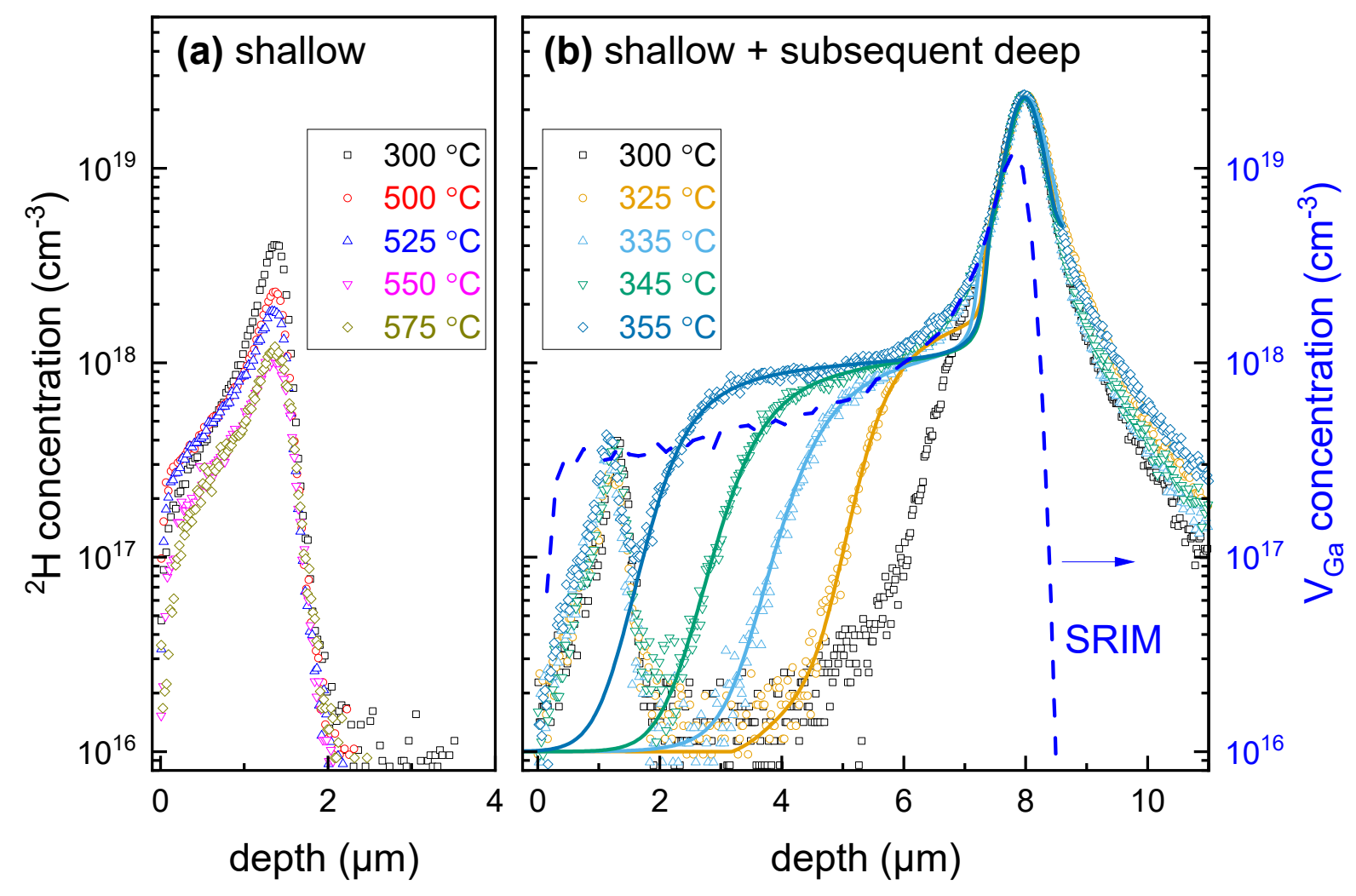


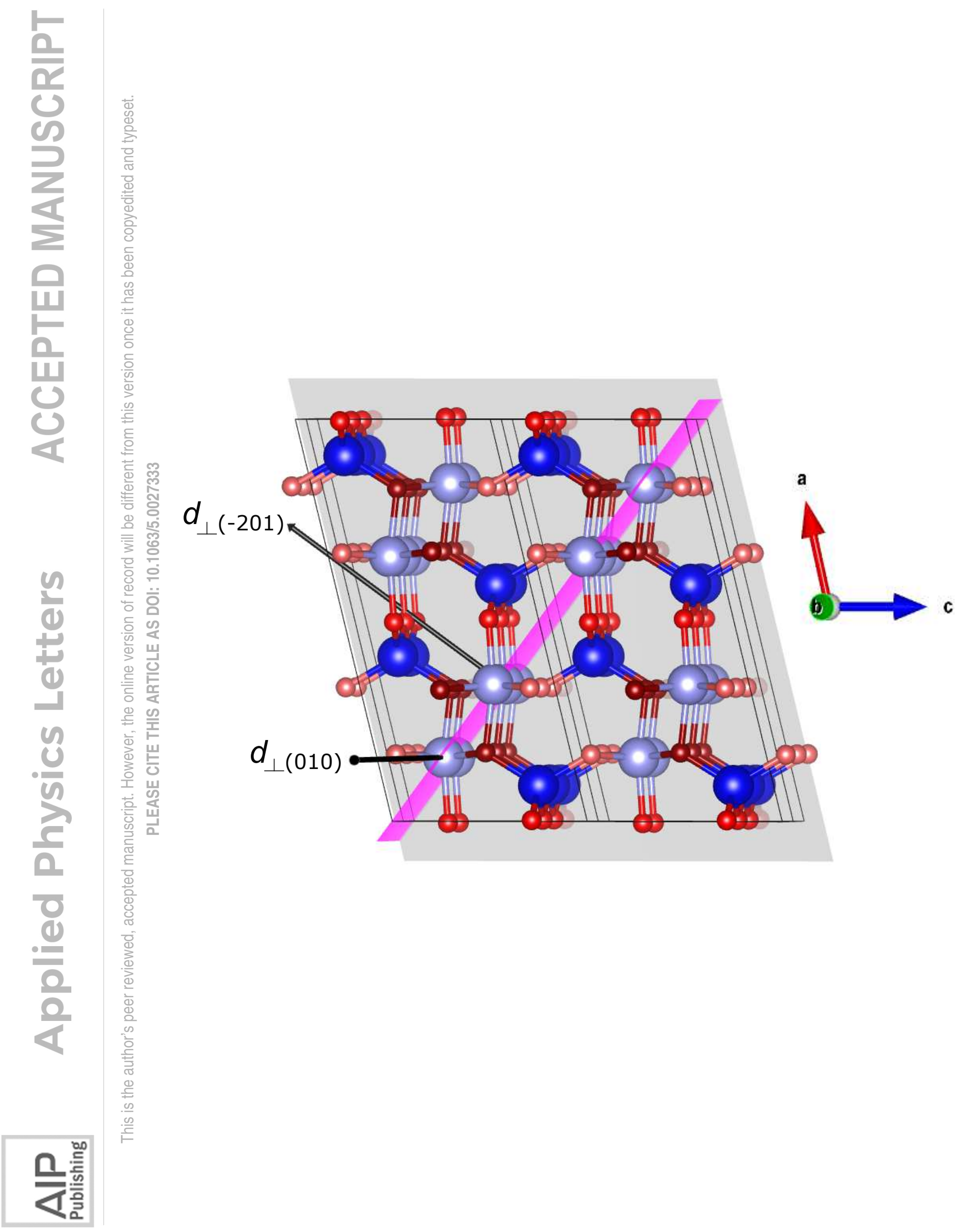

